\title{
A Case Report on Steroid Induced Acneiform Eruptions
}

\author{
Kavipriya Jeyaraj ${ }^{1}$, Megha Krishnakumar ${ }^{1 *}$, Velusamy Sivakumar ${ }^{1}$, Leelakrishnan Venkatakrishnan ${ }^{2}$ \\ ${ }^{1}$ Department of Pharmacy Practice, PSG College of Pharmacy, Coimbatore, Tamil Nadu, INDIA \\ ${ }^{2}$ Department of Gastroenterology, PSG hospitals, Coimbatore, Tamil Nadu, INDIA
}

\begin{abstract}
Acne is the chronic inflammatory disease of the pilosebaceous unit, characterized by the formation of comedones, erythematous papules and pustules shortly after starting topical or oral corticosteroid. We report a case of acneiform eruptions on a Eosinophilic gastroenteritis (EGE) patient who was treated with prednisolone 30 mg 1-0-0, 2 weeks, three months ago. She developed pustular rashes over the face and back on and off during past 3 months. Presently she got admitted in the gastroenterology department for reoccurence of the symptoms associated with EGE and treated with prednisolone $30 \mathrm{mg}$ 1-0-0. Dermatology opinion was sought for the aggravated pustular rashes over the face and back confirmed to be prednisolone induced acneiform eruptions. Following which, prednisolone was withdrawn within $48 \mathrm{~h}$ of admission and treated symptomatically with Clindamycin $1 \%$ gel.
\end{abstract}

Key words: Eosinophilic gastroenteritis, acneiform eruptions, Prednisolone, Steroids, Pustular Rashes.

\section{INTRODUCTION}

Eosinophilic gastroenteritis (EGE) is a rare and heterogeneous condition characterized by patchy or diffuse eosinophilic infiltration of gastrointestinal tissue. Prevalence of EGE is 28 per 100,000 people. Steroids remain the mainstay treatment for eosinophilic gastroenteritis.

Acneiform eruption is characterized by sudden onset of follicular papules and pustules shortly after starting topical or oral corticosteroid. ${ }^{1}$ It results from a direct effect on the follicular epithelium causing a focal degeneration with localized intrafollicular and perifollicular neutrophilic inflammatory reaction. ${ }^{2}$ Eruptions are characterized by their unusual distribution, monomorphic lesions, occurrence beyond the usual age of distribution of acne vulgaris, widespread involvement and clearing of lesions when the drug is discontinued. ${ }^{1,3}$

We report a case of prednisolone induced acneiform lesions in a 16 year old female patient.

\section{CASE REPORT}

A 16 year old female patient is known a case of eosinophilic gastroenteritis was on steroid therapy (prednisolone $30 \mathrm{mg}$ 1-0-0) for 2 weeks, three months ago. She presented with the complaints of nausea and bilious vomiting with upper abdominal pain and loose stools for two days. She developed reddish pustular rashes which had spread over both the cheeks and forehead and on the back side of shoulders on and off during past 3 months (Figure 1 and 2). She was admitted and further evaluated. An institutional ethical committee approval and informed consent was obtained.

Complete blood count showed neutrophilic leucocytosis (neutrophils 80\%) whereas the other blood parameters were normal. Serum Immunoglobulin E (558 IU/ml) was elevated. Ultra sonography of abdomen showed moderate ascites and areas of wall thickening in jejunal loops. Ascitic fluid analysis showed higher degree of eosinophilia (eosinophils 83\%). Upper GI endoscopy showed corpus and antral gastritis and gastric mucosal prolapse. Dermatol-
DOI: 10.5530ijopp.10.1.14

Address for correspondence: Megha Krishna kumar (Pharm .D), PSG College of Pharmacy Coimbatore, Tamilnadu-641004, INDIA

Phone no: 918903914470

E-mail: meghakrishnakumar23@ gmail.com 


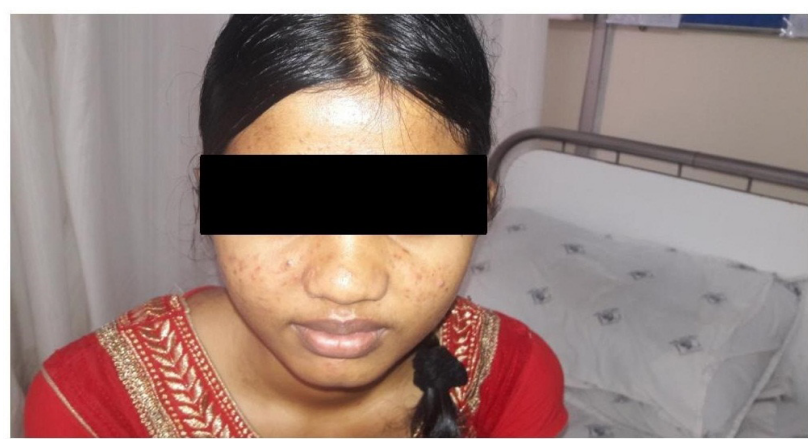

Figure 1: Prednisolone induced acneiform eruptions.

ogy opinion was sought for pustular rashes on the face and back which was hypothesized to be steroid induced acneiform eruptions, then it was assured by causality assessment at PSG Peripheral Pharmacovigilance Center, Coimbatore, TN using Naranjo ADR probability scale of 9 as prednisolone induced acneiform eruptions. ${ }^{4}$

Prednisolone was withdrawn within 48 hours of hospital admission. The patient was treated with Clear gel Clindamycin 1\% twice daily as a local applicant over the face and the back of shoulders. Inj. Pantocid (Pantoprazole) $40 \mathrm{mg}$ 1-0-0, T. Montek LC (Montelukast $10 \mathrm{mg}$ and levocetrizine $5 \mathrm{mg}$ ) 10mg 0-0-1, Inj. emeset (ondansetron) $4 \mathrm{mg}$ 1-1-1, T. Hetrazan (diethylcarbamazine) $100 \mathrm{mg}$ 1-1-1. Syrup mucaine gel (aluminium hydroxide, magnesium hydroxide, oxetacaine) $10 \mathrm{ml}$ 1-1-1, T. Ciplox (ciprofloxacin) $250 \mathrm{mg}$ 1-0-1 and T. Shelcal (calcium carbonate and vitamin $\mathrm{D}_{3}$ ) were given. On next day, the eruptions started to reduce, her clinical condition was stabilized. On the $4^{\text {th }}$ day the condition of patient got improved and was discharged. However, the topical therapy was advised to continue until complete remission of her symptoms.

\section{DISCUSSION}

Acneiform eruptions formed a major part of cutaneous adverse drug reactions accounting for $11.3 \%$ of patients. Corticosteroids were found to be the third most common drug class implicated in cutaneous adverse drug reactions accounting for $14.6 \%$ of the patients. ${ }^{5}$

Acneiform eruptions induced by steroids may be caused by topical or systemic drugs. One which caused by systemic drugs is dependent on the dose, duration of administration and patients susceptibility. ${ }^{6}$ Systemic drugs that induced acneiform eruptions include corticosteroids, epidermal growth factor receptor inhibitors, cyclosporine, anticonvulsants, antipsychotics, antidepressants, tumor necrosis factor-alpha inhibitor, anabolic steroids, danazole, anti-tuberculosis drugs, quinidine, azathioprine and testosterone. ${ }^{3}$

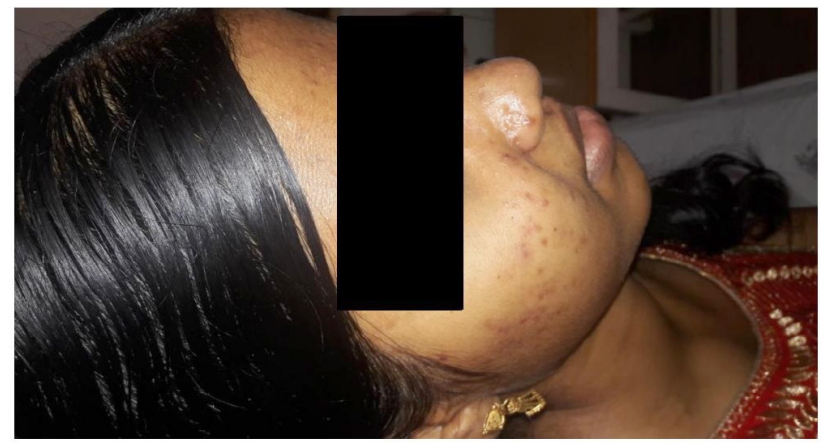

Figure 2: Pustular rashes over right side cheeks.

Acneiform eruptions are non-allergic reactions, in most cases the exact etiology and pathogenesis remains unknown. Therefore skin test is not useful in the diagnosis of drug induced acne. The patient's history, the clinical findings, the exposure to one of the known causative drugs and the disappearance of lesions after discontinuation of the offending medication should lead to the diagnosis. ${ }^{2}$ Female sex is nearly 4 times more prone to steroid induced acne than the male sex. ${ }^{3,7}$ Acne was subsided following discontinuation of drug within a week, though severe lesions may take several weeks to resolve and may require topical therapy. ${ }^{1,3}$ The use of antihistamines is important when there is associated pruritis and oral antibiotics should be used in cases of secondary infection with pustules or impetiginization. ${ }^{3}$ In our study, acneiform eruptions associated pruritis were managed by T.Monteleukast LC

\section{CONCLUSION}

Every health care practitioner should recognize the common presentation and appearance of adverse drug reaction associated with steroids. And thus for each patient, the risk must be weighed against the expected therapeutic benefit. ${ }^{9}$

\section{ACKNOWLEDGEMENT}

We would like to express sincere gratitude to Dr.L Venkatakrishnan, Head of the Department of Gastroenterology, PSG Hospitals, Coimbatore as well as Dr.V.Sivakumar, Assistant Professor,Department of Pharmacy practice, PSG College of Pharmacy who helped us all through the framework of our study.

\section{CONFLICT OF INTEREST}

None

\section{ABBREVIATIONS USED}

Indian Journal of Pharmacy Practice, Vol 10, Issue 1, Jan-Mar, 2017 
ADR: adverse drug reaction; TN: tamil nadu; EGE: eosinophilic gastroenteritis; GI: gastrointestine.

\section{REFERENCES}

1. Sinha S, Udupa S, Bhandary RP, Praharaj SK, Munoli RN. Sertraline-Induced Acneiform Eruption. J Neuropsychiatry Clin Neurosci Spring. 2014;26(2):E567.

2. Plewig G, Jansen T. Acneiform Dermatoses Dermatology. Health \& Medical Collection 1998;196(1):102-7.

3. Balta I, Ozuguz P. Vitamin B12-induced acneiform eruption. Cutaneous and Ocular Toxicology. 2014;33(2):94-5. https://doi.org/10.3109/15569527.2013.80 8657 ; PMid:23815241

4. Naranjo CA, Busto $U$, Sellers EM, et al: A method for estimating the probability of adverse drug reactions. Clin Pharmacol Ther 1981;30:239-45. https://doi. org/10.1038/clpt.1981.154
5. Sharma R, Dogra D, Dogra N. A Study of cutaneous adverse drug reactions at a tertiary center in Jammu, India. Indian Dermatol Online J. 2015;6(3):168-71. https://doi.org/10.4103/2229-5178.156384 ; PMid:26009710 PMCid:PMC4439744.

6. Rosa DJF, Matias FAT, Machado SM, Alessandra Almeida Montenegro de Sá, Vânia Carolina Piccinini Silva. Acute acneiform eruption induced by interferon beta-1b during treatment for multiple sclerosis. An Bras Dermatol. 2011;86(2):336-8. https://doi.org/10.1590/S0365-05962011000200018 ; PMid:21603818.

7. Ravishankar M, Shwetha S, Deepika G. Metasone furoate induced acneiform eruption. International Journal of Basic \& Clinical Pharmacology. 2014;3(4):7367. https://doi.org/10.5455/2319-2003.ijbcp20140818.

8. Momin S, Peterson A, Rosso JQD. Drug-Induced Acneform Eruptions: Definitions and Causes. Cosmetic Dermatology 2009;22(1):28-37.

9. Raksha MP, Marfatia YS. Clinical study of cutaneous drug eruptions in 200 patients. Indian J Dermatol Venereol Leprol 2008; 74:80. https://doi. org/10.4103/0378-6323.38431. 